\title{
Pemanfaatan Potensi Energi Aliran Kanal Kalisolo I Pada Pusat Pengembangan Sumber Daya Manusia Minyak Dan Gas Bumi
}

\author{
Ahmad Nawawi dan Sonden Winarto \\ Pusat Pengembangan Sumber Daya Manusia Minyak dan Gas Bumi, Cepu
}

\begin{abstract}
ABSTRAK
Untuk pemenuhan akan kebutuhan air bersih pada PPSDM Migas, yang rata-rata setiap harinya membutuhkan air sebanyak 3,250 m3, menggunakan air dari Bengawan Solo, yang diolah di bagian pengolahan air, dengan memompa dan menyalurkannya melalui sebuah kanal sebelum masuk ke kolam (bak) pengolahan. Aliran air pada kanal ini terdapat potensi energy sebagai pembangkit listrik. Pada penelitian ini dilakukan rancang bangun pemanfaatan kanal kalisolo 1 PPSDM Migas, untuk Pembangkit Listrik Tenaga Hidrokinetik (PLTHk) dan/atau Pembangkit listrik tenaga piko hidro (PLTPH) dengan menggunakan Turbin Open Flume. Setelah dilakukan pengukuran pada obyek serta dianalisa, maka pada obyek I dengan luas penampang $1 \mathrm{~m} \mathrm{x} 0.35 \mathrm{~m}$, kecepatan arus air kanal $0.8 \mathrm{~m} / \mathrm{s}$, didapatkan potensial daya sebesar $89.6 \mathrm{~W}$. Pada obyek II dengan luas penampang $0.4 \mathrm{~m} \times 0.4$ $\mathrm{m}$, kecepatan arus air kanal $0.4 \mathrm{~m} / \mathrm{s}$, didapatkan potensial daya sebesar $5.12 \mathrm{~W}$, bila menggunakan PLTHk. Sedang bila direncanakan Pembangkit listrik tenaga piko hidro (PLTPH) dengan menggunakan Turbin Open Flume, dengan asumsi head air 2 m, pada obyek I dapat dihasilkan daya listrik sebesar $494.424 \mathrm{~W}$ atau $0.5 \mathrm{~kW}$, dan bila asumsi head air $1 \mathrm{~m}$, dapat terbangkit daya listrik 247.212 Watt atau $0.25 \mathrm{~kW}$, dengan efisiensi generator 0,9 dan efisiensi turbin 0,9 , sedang pada obyek II tidak dapat direncanakan PLTPH Turbin Open Flume, karena sulit untuk mendesain head air.
\end{abstract}

Kata Kunci: Potensial energy, PLTHk, PLTPH Open Flume.

\begin{abstract}
This is used to fulfill the demand of clear water in PPSDM Migas which needs 3,250 m3 water in average using Bengawan Solo river to be processed in water process by pumping and distributing through a channel before entering into a processing tank. Water flows from this channel may result potential energy as a power plant. From this research, it will be made a design of canal utilization in Kalisolo 1 in PPSDM Migas to generate Hydrokinetic Power Plant and/or Piko Hydro Power Plant by using Open Flume Turbine. After measuring and anylizing it, then in object 1 with cross sectional area $1 \mathrm{~m} \times 0.35$ $m$, speed of canal water flow is $0.8 \mathrm{~m} / \mathrm{s}$, its power potential is equal to $89.6 \mathrm{~W}$. In object 2, with cross sectional area $0.4 \mathrm{~m} \times 0.4 \mathrm{~m}$, speed of canal water flow is $0.4 \mathrm{~m} / \mathrm{s}$, its power potential is equal to $5.12 \mathrm{~W}$, when using Hydro Kinetic Power Plant. Whereas if Piko Hydro Power Plant uses Open Flume Turbine with an assumption of head air is $2 \mathrm{~m}$, object 1 can result electric power of $494.424 \mathrm{~W}$ or $0.5 \mathrm{~kW}$, and if an assumption of head air is $1 \mathrm{~m}$, the electric power is 247.212 Watt or $0.25 \mathrm{~kW}$, with generator efficiency is 0,9 and turbine efficiency 0,9, meanwhile in object 2 cannot be planned Piko Hydro Power Plant with Flume Open Turbine since there is difficulty in designing water head.
\end{abstract}

Keywords: Energy Potential, Hydrokinetic Power Plant, Open Flume Micro Hydro Power Plant

Email : Ahmad.Nawawi@esdm.go.id 


\section{PENDAHULUAN}

\section{A. Latar Belakang}

Teknologi air sebagai pembangkit listrik tenaga air skala kecil merupakan salah satu teknologi yang pemanfaatan energinya handal dengan biaya yang relatif murah, serta penyediaan energi yang ramah lingkungan. Energi potensial air (Hydropower) merupakan salah satu energi yang paling banyak di gunakan sebagai pembangkit energi listrik, seperti pembangkit listrik tenaga piko hidro (PLTPH). Turbin air merupakan alat pengubah energi potensial air menjadi energi mekanik yang dapat dimanfaatkan sebagai penggerak generator (Lubis, 2007). Pembangkit listrik tenaga hidrokinetik menggunakan turbin Vertikal Axis tipe Darrieus Straight Blade Cascade, energy potensial yang dirubah menjadi energy kinetic hanya memanfaatkan kecepatan aliran sungai. Sedang pembangkit listrik tenaga mikro hidro menggunakan turbin propeller open flume merupakan suatu pembangkit yang memanfaatkan aliran sungai yang memiliki head yang rendah sebagai tenaga penggeraknya. Mikro hidro dengan menggunakan turbin propeller open flume tidak memerlukan pipa penstok dan konstruksi rumah pembangkit (Nugraha, 2013). Turbin propeller open flume merupakan turbin reaksi yang beroperasi pada head rendah yaitu kurang dari 6 meter. Turbin propeller open flume memiliki konstruksi yang sederhana dan harga yang relatif murah (Paisey, 2010).

Kanal Kalisolo 1 PPSDM Migas merupakan salah satu obyek yang memiliki potensi tenaga air dan diperkirakan dapat menghasilkan energi listrik sebesar 494.424 Watt, sementara potensi tersebut belum dimanfaatkan.

Dengan adanya perencanaan pembangkit energi listrik yang memanfaatkan energi air kanal kalisolo 1, sebagai penggeraknya diharapkan dapat menjadi percontohan kepada masyarakat, dan peserta pelatihan yang ada di PPSDM Migas akan pemanfaatan potensi yang ada. Untuk pembangkit listrik berskala kecil seperti Pembangkit Listrik Tenaga Hidrokinetik (PLTHk), dan Pembangkit listrik tenaga piko hidro (PLTPH) dengan menggunakan turbin propeller open flume sangatlah tepat untuk dioperasikan pada head yang rendah, dikarenakan tenaga yang diperlukan untuk penggerak turbin dengan memanfaatkan daya hisap draft tube yang vacum.

Penelitian ini bertujuan untuk memanfaatkan potensi energi air yang selama ini belum dimanfaatkan, sehingga mampu menghasilkan energi listrik melalui perencanaan PLTHk dan PLTPH menggunakan turbin propeller open flume.

\section{B. Rumusan Masalah}

Beberapa masalah yang terkait dengan penelitian Pemanfaatan Aliran Kanal Kalisolo I untuk Pembangkit Listrik Tenaga Hidrokinetik (PLTHk) Pada Pusat Pengembangan Sumber Daya Manusia Minyak Dan Gas Bumi, adalah:

a. Apa yang dimaksud dengan PLTHk dan PLTPH?

b. Berapa besar daya listrik yang tergolong PLTMH ?

c. Berapa besar daya listrik yang terbangkitkan pada rangcangan PLTHk dan PLTPH ?

d. Peralatan/komponen apa saja yang diperlukan dalam perencanaan PLTHk dan PLTPH ini ?

e. Apa tujuan dari penelitian ini ?

\section{Batasan Masalah}

Berikut ini merupakan batasan masalah yang terkait dengan penelitian Pemanfaatan Aliran Kanal Kalisolo I untuk Pembangkit Listrik Tenaga Hidrokinetik (PLTHk) Pada Pusat Pengembangan Sumber Daya Manusia Minyak Dan Gas Bumi :

a. Penelitian hanya terfokus pada titik pengamatan, yaitu pada dua obyek Aliran Kanal Kalisolo I, Pusat Pengembangan Sumber Daya Manusia Minyak dan Gas Bumi.

b. Penelitian hanya menentukan daya listrik yang dapat dibangkitkan, berdasarkan data yang didapat dari lapangan dan dihitung dengan menggunakan formulasi dari referensi, serta kebutuhan peralatan yang diperlukan secara umum, belum menentukan kapasitas pada tiap-tiap peralatan.

c. Pengukuran dan pengumpulan data dilakukan pada bulan Agustus - September 2018. 


\section{Tujuan Penelitian}

Perencanaan secara teoritis dari penelitian ini adalah :

a. Untuk mengetahui yang dimaksud dengan PLTHk dan PLTPH

b. Mengetahui klasifikasi jenis Pembangkit Tenaga Listrik

c. Untuk mengetahui besar daya listrik yang dapat terbangkitkan untuk perencanaan PLTHk dan PLTPH di kanal kalisolo I ini.

d. Mengetahui peralatan/komponen yang diperlukan dalam PLTHk dan PLTPH

e. Untuk mengetahui potensial energy, yang sering diabaikan, walau pada sekala kecil.

\section{E. Manfaat Penelitian}

Manfaat dari penelitian ini adalah :

a. Memanfaatkan potensi energy yang belum di optimalkan, yang tersedia disekitar kita.

b. Sebagai proyek percontohan kepada peserta diklat maupun masyarakat akan pemanfaatan potensi energy, sekaligus dapat ikut serta dalam program pemerintah untuk mengembangkan energi baru terbarukan.

\section{TINJAUAN PUSTAKA}

A. Pembangkit Listrik Tenaga Air

1. Pengertian dan Klasifikasi Pembangkit Listrik Tenaga Air

Penggunaan energi air sebagai sumber energi sudah dilakukan sejak lama, salah satunya dimanfaatkan untuk pembangkit listrik tenaga air. Pembangkit listrik tenaga air memanfaatkan energi potensial dan energy kinetik air yang dikonversikan menjadi daya angular oleh turbin air. Sederhananya air yang bergerak menggerakkan turbin, turbin memutar generator dan energi listrik dihasilkan. Banyak komponen lain terdapat dalam sistem tetapi semuanya dimulai dengan energi pada air tersebut.

Pemanfaatan pembangkit listrik tenaga air diklasifikasikan menurut besarnya kapasitas daya yang dihasilkan. Klasifikasi umum pembangkit listrik tenaga air mengikuti sebagai berikut (Penche \& Minas, 1998) :
Tabel 1. klasifikasi pembangkit listrik tenaga air

\begin{tabular}{|l|l|}
\hline \multicolumn{1}{|c|}{ Tipe } & \multicolumn{1}{c|}{ Kapasitas } \\
\hline Piko Hidro & $<5 \mathrm{~kW}$ \\
\hline Mikro Hidro & $5-100 \mathrm{~kW}$ \\
\hline Mini Hidro & $100-1000 \mathrm{~kW}$ \\
\hline Small Hidro & $1-15 \mathrm{MW}$ \\
\hline Medium Hidro & $15-100 \mathrm{MW}$ \\
\hline Large Hidro & $>100 \mathrm{MW}$ \\
\hline
\end{tabular}

Dari tabel 1 pembangkit listrik tenaga pikohidro (PLTPH) merupakan pembangkit air yang memiliki kapasitas $<5 \mathrm{~kW}$. Pembangkit listrik tenaga pikohidro (PLTPH) merupakan tipe pembangkit tenaga air yang sesuai diterapkan di lokasi-lokasi yang memiliki tinggi jatuh rendah dan aliran air yang tidak terlalu banyak. Sebagai sumber energy terbarukan, PLTPH bisa menjadi salah satu alternatif penyediaan energy listrik yang ramah lingkungan.

\section{Daya Hidraulik Tenaga Air}

Daya hidraulik yang akan dikeluarkan dari air yang jatuh dinyatakan dengan persamaan berikut :

$$
\text { Pair } \quad=\rho \times g \times Q \times H \text {. }
$$

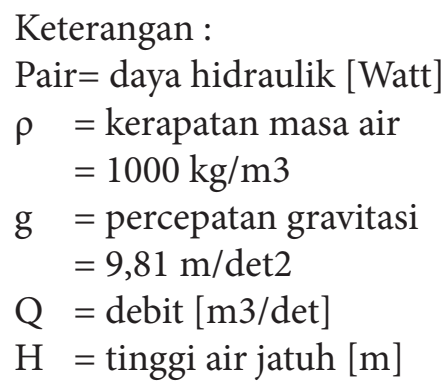

Daya turbin yang dihasilkan :

$$
\text { Pt }=\eta t \times \text { T } x \text { Pair }
$$

Keterangan :

$\mathrm{Pt}$ = daya turbin [Watt],

$\mathrm{T}=$ jumlah nozle

$\mathrm{Ht}=$ Efisiensi Turbin

Apabila ditinjau dari kapasitasnya dan tinggi jatuh air, daya generator yang direncanakan dapat ditentukan dengan persamaan. 


$$
\mathrm{Pg}=\rho \times \mathrm{g} \times \mathrm{Q} \times \mathrm{H} \times \eta \mathrm{t}
$$

Keterangan :

$\mathrm{Pg}$ = daya generator ........(W)

$\rho=$ massa jenis ...... $(\mathrm{kg} / \mathrm{m} 3)$

$\mathrm{g}=$ percepatan gravitasi $(\mathrm{m} / \operatorname{det} 2)$

$\mathrm{Q}=$ debit aliran air (m3/det)

$\mathrm{H}$ = tinggi air jatuh $(\mathrm{m})$

$\eta \mathrm{t}=$ efisiensi turbin (untuk turbin air harga effisiensi 84\% s/d 94\%)

\section{B. Pembangkit Listrik Tenaga Hidrokinetik (PLTHk)}

Pembangkit listrik tenaga hidrokinetik (PLTHk) adalah pembangkit listrik yang memanfaatkan kecepatan aliran air, tanpa memperhitungkan head atau beda tinggi aliran air, dengan menggunakan turbin jenis Vertikal Axis tipe Darrieus Straight Blade Cascade. Secara garis besar PLTHk terdiri dari beberapa bagian/peralatan seperti gambar 1 .

Energi kinetik air yang dapat masuk ke dalam area efektif turbin dapat dihitung berdasarkan persamaan 4 (XPowered By Albireo) berikut :

$$
P=\frac{\rho \cdot A \cdot V^{3}}{2}
$$

\section{Dimana :}

$\mathrm{P}$ = Daya yang dibangkit-kan.......Watt

$\rho=$ Massa jenis air ........ Kg/m3

$\mathrm{A}=$ Luas penampang kanal , $\mathrm{m} 2$

$\mathrm{V}=$ Kecepatan aliran air ....m/s

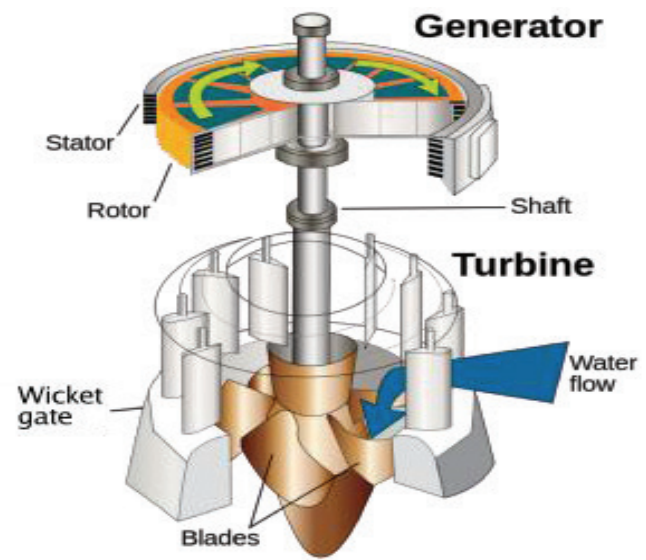

Gambar 1. Jenis turbin untuk PLTHk

\section{Pembangkit listrik tenaga pikohidro (PLTPH) Turbin Open Flume}

Pembangkit listrik tenaga piko hidro (PLTPH) adalah pembangkit listrik berskala kecil dengan output di bawah $5 \mathrm{~kW}$ yang memanfaatkan potensi aliran air yang terdapat di pedesaan sebagai sumber tenaga misalnya saluran irigasi, sungai atau air terjun alam. PLTPH memiliki konstruksi yang sederhana, mudah dioperasikan, mudah dalam perawatan serta dengan biaya investasi yang terjangkau sehingga cocok diterapkan untuk menerangi wilayah pedesaan yang tidak terjangkau aliran listrik PLN, atau memanfaatkan energy potensial yang belum dimanfaatkan.

Secara teknis, pembangkit listrik tenaga piko hidro memiliki tiga komponen utama yaitu air (sebagai sumber energi), turbin dan generator. Pembangkit listrik tenaga pikohidro mendapatkan energi dari aliran air yang memiliki perbedaan ketinggian tertentu. Pada dasarnya, pembangkit listrik tenaga mikro hidro memanfaatkan energi potensial jatuhan air (head). Semakin tinggi jatuhan air maka semakin besar energi potensial air yang dapat diubah menjadi energi listrik. Pembangkit listrik tenaga pikohidro bisa memanfaatkan ketinggian air yang tidak terlalu besar, misalnya dengan ketinggian air 2,5 $\mathrm{m}$ dapat dihasilkan listrik 400 W. Prinsip kerja PLTPH adalah memanfaatkan beda tinggi dan jumlah debit air per detik yang ada pada aliran atau sungai. Air yang mengalir melalui intake dan diteruskan oleh saluran pembawa hingga penstock, akan memutar poros turbin sehingga menghasilkan energi mekanik. Turbin air akan memutar generator dan menghasilkan listrik.

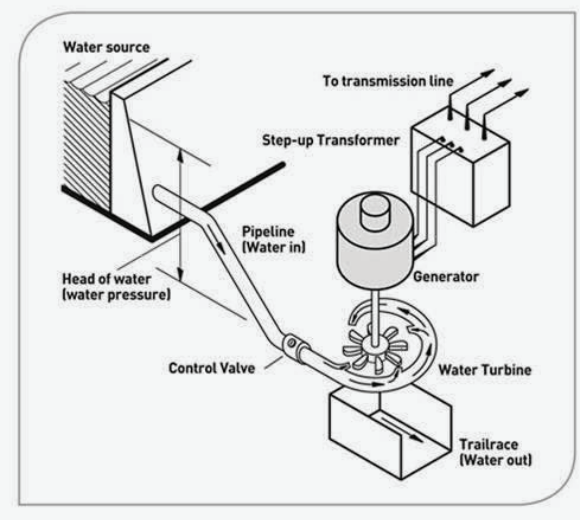

Gambar 2 Prinsip Kerja PLTPH 
Sedang PLTPH yang hanya mempunyai head atau ketinggian air dibawah $2.5 \mathrm{~m}$, jenis turbin yang dipilih adalah jenis turbin open flume, seperti pada gambar 3 dibawah :

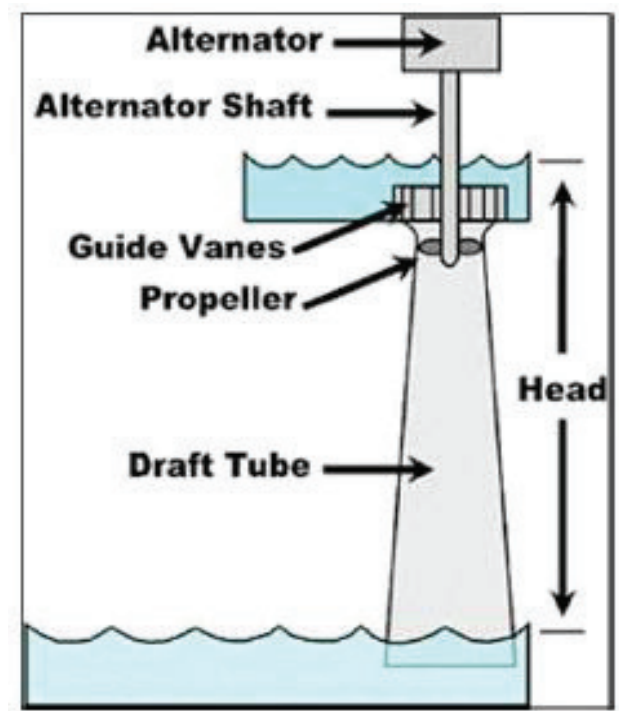

Gambar 3 PLTPH dengan turbin Open Flume

\section{Komponen / peralatan yang diperlukan}

Dengan melihat hasil perhitungan daya listrik yang dapat dibangkitkan dari kedua system pembangkit, maka pembangkit listrik tenaga mikro hidro dengan turbin openflume yang lebih baik, dilihat dari perbandingan biaya yang diperlukan dengan daya yang terbangkitkan.

Untuk merencanakan pembangkit listrik tenaga pikohidro (PLTPH) dengan turbin open flume diperlukan beberapa peralatan/komponen sebagai berikut :

\section{Draft Tube}

Draft tube ini berupa sebuah pipa, baik pipa PVC ataupun juga bisa pipa besi, yang berfungsi untuk mendapatkan ruang vakum antara propeller turbin dengan aliran kanal, dengan head yang direncanakan 2 meter.

\section{Turbin Open Flume (Propeller)}

Dalam membangun Pembangkit Listrik Mikrohidro, maka pemilihan jenis turbin cukup penting dan menentukan. Turbin air berperan untuk mengubah energi air (energi potensial, tekanan dan energi kinetik) menjadi energi mekanik dalam bentuk putaran poros. Putaran poros turbin ini akan diubah oleh generator menjadi tenaga listrik.

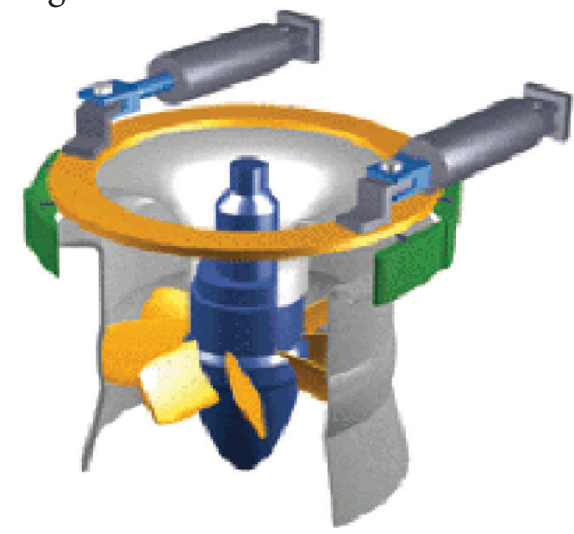

Gambar 4. Turbin Open Flume (Propeller)

Pemilihan jenis turbin dapat diperhitungkan dengan mempertimbangkan parameter-parameter tertentu yang mempengaruhi sistem operasi turbin, yaitu :

- Faktor tinggi jatuhan air efektif (Net Head) dan debit yang akan dimanfaatkan untuk operasi turbin merupakan faktor utama yang mempengaruhi pemilihan jenis turbin, sebagai contoh turbin pelton efektif untuk operasi pada head tinggi, sementara turbin propeller sangat efektif beroperasi pada head rendah.

- Faktor daya (power) yang diinginkan berkaitan dengan head dan debit yang tersedia.

- Kecepatan (putaran) turbin ang akan ditransmisikan ke generator. Sebagai contoh untuk sistem transmisi direct couple antara generator dengan turbin pada head rendah, sebuah turbin reaksi (propeller) dapat mencapai putaran yang diinginkan, sementara turbin pelton dan crossflows saat berputar sangat lambat (low speed) yang akan menyebabkan sistem tidak beroperasi.

Tabel 2. Pemilihan Jenis Turbin Berdasarkan Head (Tinggi Jatuhan Air)

$\begin{array}{lc}\text { Jenis Turbin } & \text { Variasi Head, m } \\ \text { Kaplan dan Propeller } & 2<\mathrm{H}<20 \\ \text { Francis } & 10<\mathrm{H}<350 \\ \text { Pelton } & 50<\mathrm{H}<1000 \\ \text { Crossfiow } & 6<\mathrm{H}<100 \\ \text { Turgo } & 50<\mathrm{H}<250\end{array}$




\section{Gearbox}

Gearbox adalah perangkat mekanikal yang digunakan untuk meningkatkan torsi dan mengurangi atau menambah kecepatan atau RPM dari motor.

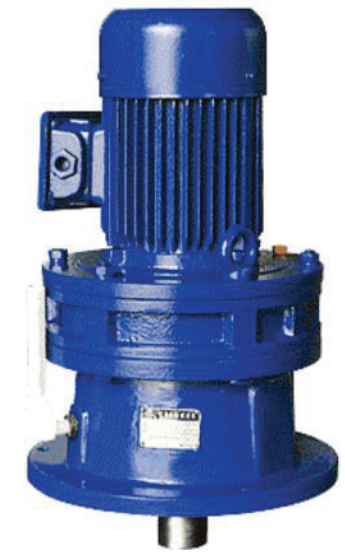

Gambar 5. Gearbox vertical

Pada pembangkit listrik tenaga pikohidro (PLTPH) Open Flume, Gearbox dipasang antara turbin dan generator, yang fungsinya untuk menyesuaikan putaran yang diperlukan pada unit generator.

\section{Generator}

Generator adalah sumber tegangan listrik yang diperoleh melalui perubahan energi mekanik menjadi energi listrik. Generator bekerja berdasarkan prinsip induksi elektromagnetik, yaitu dengan memutar suatu kumparan dalam medan magnet sehingga timbul ggl induksi. Generator mempunyai dua komponen utama, yaitu bagian yang diam (stator) dan bagian yang bergerak (rotor). Rotor dihubungkan dengan poros generator yang berputar di pusat stator. Poros generator diputar menggunakan usaha luar yang berasal dari turbin open flume melalui gearbox, selanjutnya berproses menghasilkan arus listrik.

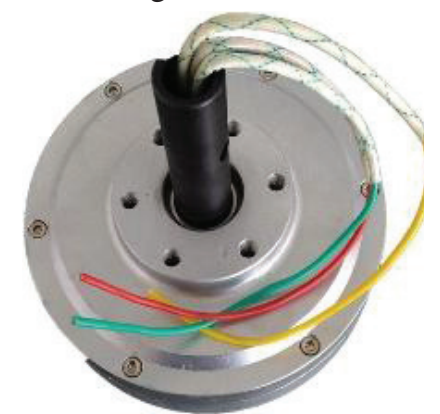

Gambar 6a. Generator vertical magnet permanen

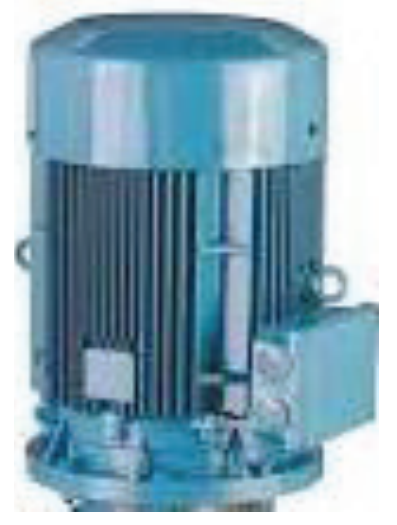

Gambar 6b. Motor induksi vertical

Untuk mendapatkan tegangan dan arus listrik pada PLPH open flume, selain dengan menggunakan generator, bisa juga digunakan motor induksi, baik motor induksi satu phasa maupun tiga phasa.

\section{Penstabil Tegangan}

Untuk menjaga kualitas dari tegangan yang dihasilkan dari generator pada pembangkit listrik tenaga pikohidro (PLTPH) turbin open flume diperlukan suatu alat penstabil tegangan. Dengan dua atau tiga konduktor, Output tegangan dari generator dihubungkan ke penstabil tegangan, dan output dari alat penstabil tegangan dihubungkan dengan sisi primer dari sebuah transformator.

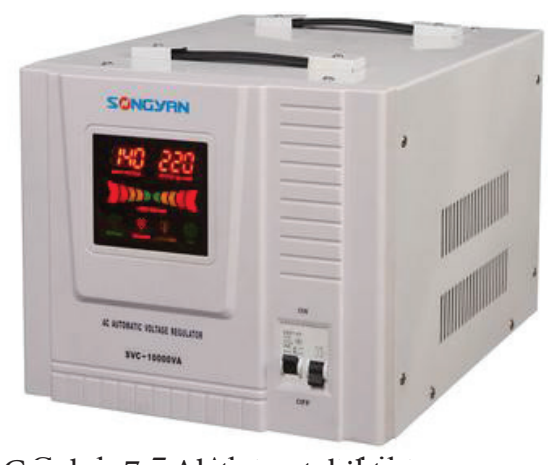

Gãmbar 7. - Alat penstabil tëgangan

\section{Transformator}

Transformator atau sering disingkat dengan istilah Trafo adalah suatu alat listrik yang berfungsi untuk menyalurkan daya listrik dari satu rangkaian ke rangkaian yang lain tanpa merubah daya listrik, namun pada tegangan dan arus yang berbeda, berdasarkan prinsip induksi magnet. 
Dilihat dari besaran tegangan pada trafo, Trafo terdiri dari dua jenis, yaitu trafo step-up dan trafo step-down. Trafo step up digunakan sebagai penaik tegangan. Sedangkan trafo step down digunakan sebagai penurun tegangan.

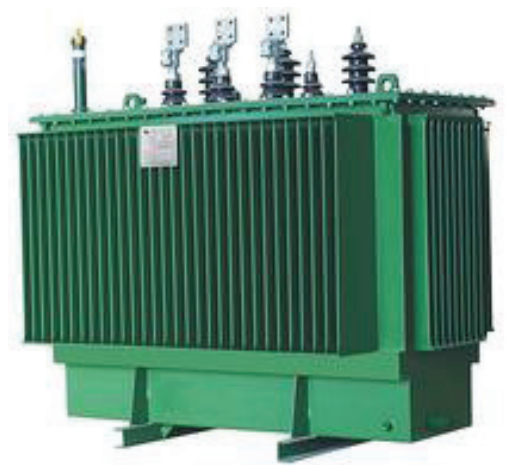

Gambar 8. Bentuk phisik transformator 3 phasa

Pembangkit listrik mikro hidro menggunakan trafo step up untuk menaikkan tegangan sesuai kebutuhan pengguna listrik. Pada dasarnya trafo memiliki dua buah kumparan, yaitu kumparan primer dan kumparan sekunder, serta inti besi yang berlapis-lapis sebagai tempat atau dudukan kumparan tersebut.

Bila kita menghendaki trafo tersebut akan digunakan sebagai trafo step up, maka jumlah kumparan harus lebih banyak pada sisi sekunder, begitu juga sebaliknya, bila dikehendaki untuk step down, maka kumparan sisi primer harus lebih banyak dibanding pada sisi sekunder. Berikut adalah jumlah perbandingan kumparan terhadap tegangan dan arus listriknya.

$$
\frac{N p}{N s}=\frac{V p}{V s}=\frac{I s}{I p}
$$

Dimana :

$\mathrm{Np}=$ Jumlah kumparan pada sisi primer

Ns = Jumlah kumparan pada sisi sekunder

$\mathrm{Vp}=$ Tegangan pada sisi primer

Vs = Tegangan pada sisi sekunder

Ip = Arus pada sisi primer

Is = Arus pada sisi sekunder

Jadi secara schematic kelengkapan pembangkit listrik tenaga mikro piko (PLTPH) dengan turbin open flume, seperti terlihat pada gambar 9. dibawah.

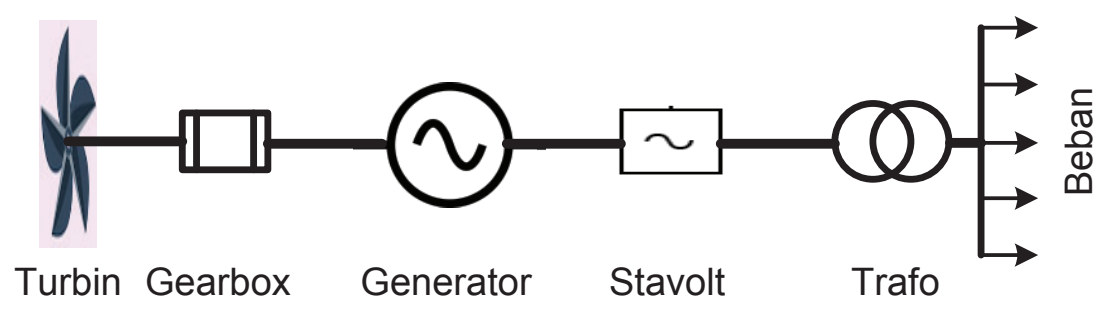

Gambar 9. Gambar Schematic Peralatan PLTPH Open Flume

\section{METODOLOGI PENELITIAN}

Penelitian ini dilakukan secara bertahap, berikut tahapan yang dilakukan dalam penulisan ini, dapat dilihat pada Gambar 10 :

Tahap pemilihan lokasi merupakan tahapan yang dilakukan oleh penulis untuk menentukan dimana lokasi untuk pengambilan data yang akan diteliti. Setelah ditentukan lokasi yang akan digunakan maka tahapan selanjutnya adalah mengukur parameter-parameter penting seperti luas penampang, debit air dan head efektif pada lokasi tersebut untuk menghitung potensi energy listrik yang dihasilkan dari PLTHk maupun PLTPH turbin Open Flume. 


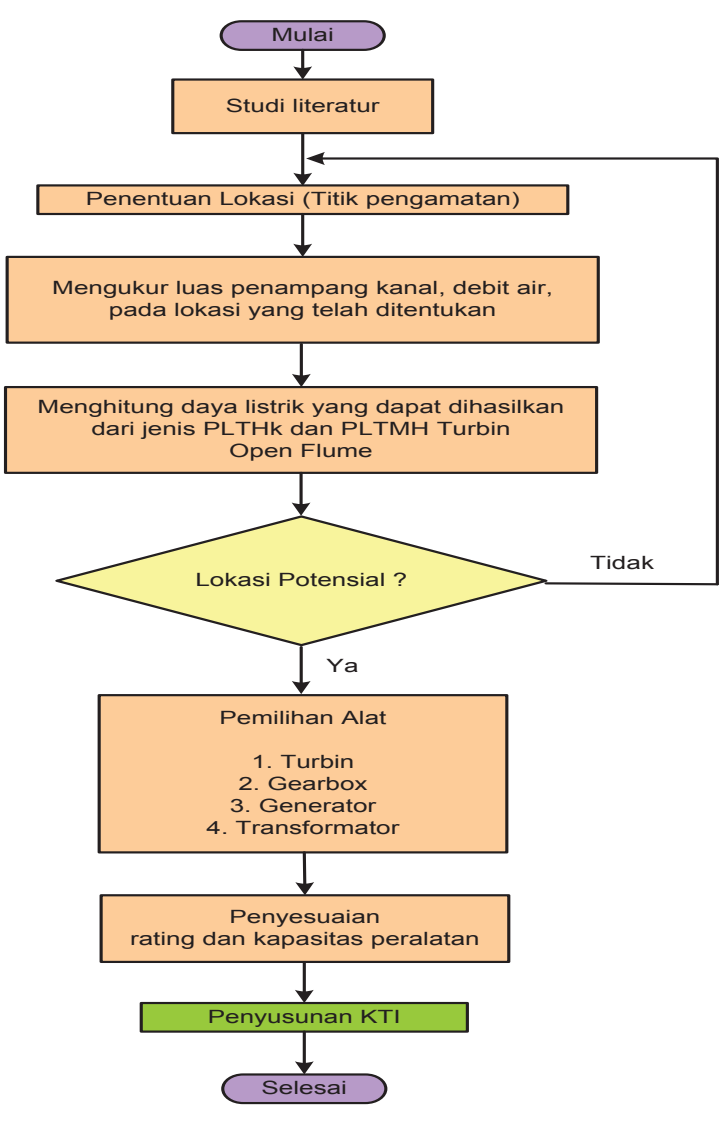

Gambar 10. Diagram alir penelitian

Selanjutnya tahapan yang akan dilakukan yaitu menentukan jenis serta rating dari komponen-komponen yang diperlukan, sesuai dengan lokasi tempat pengambilan data, bila ketersedian peralatan sudah sesuai dengan hasil-hasil perhitungan, maka tahap selanjutnya adalah penulisan dalam bentuk Karya Tulis Ilmiah.

\section{PEMBAHASAN}

\section{A. Pengukuran}

Penentuan titik pengamatan atau obyek penelitian merupakan langkah awal didalam melakukan penelitian ini. Selanjutnya melakukan pengukuran-pengukuran untuk mendapatkan data yang diperlukan, seperti gambar dibawah :

Dari pengukuran yang telah dilakukan, didapatkan hasil sebagai berikut ;

a. Titik pengamatan I ;

- lebar kanal $1 \mathrm{~m}$

- kedalaman air $0.35 \mathrm{~m}$

- kecepatan aliran air kanal $0.8 \mathrm{~m} / \mathrm{s}$ (diukur 2 meter setelah outflow)

b. Titik pengamatan II ;

- lebar kanal $0.4 \mathrm{~m}$

- kedalaman air $0.4 \mathrm{~m}$

- kecepatan aliran air kanal $0.4 \mathrm{~m} / \mathrm{s}$

\section{B. Menghitung daya listrik terbangkitkan}

1. Pembangkit Listrik Tenaga Hidrokinetik (PLTHk)

Dari data yang didapatkan, maka dengan menggunakan persamaan (4) didapatkan hasil sebagai berikut :
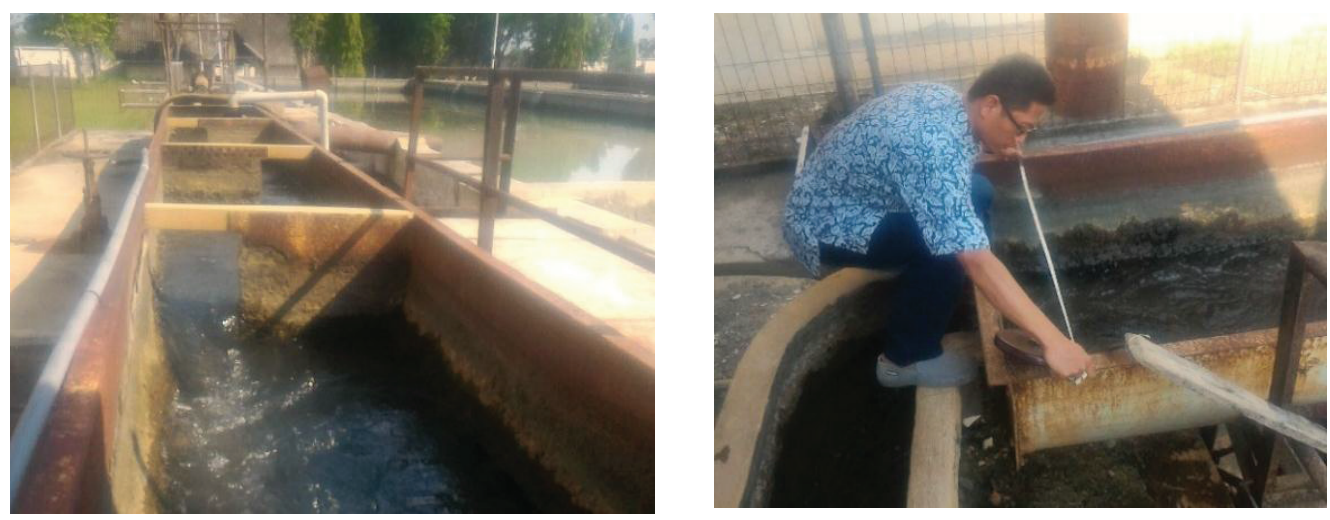

Gambar 11. Pengukuran pada titik pengamatan I 

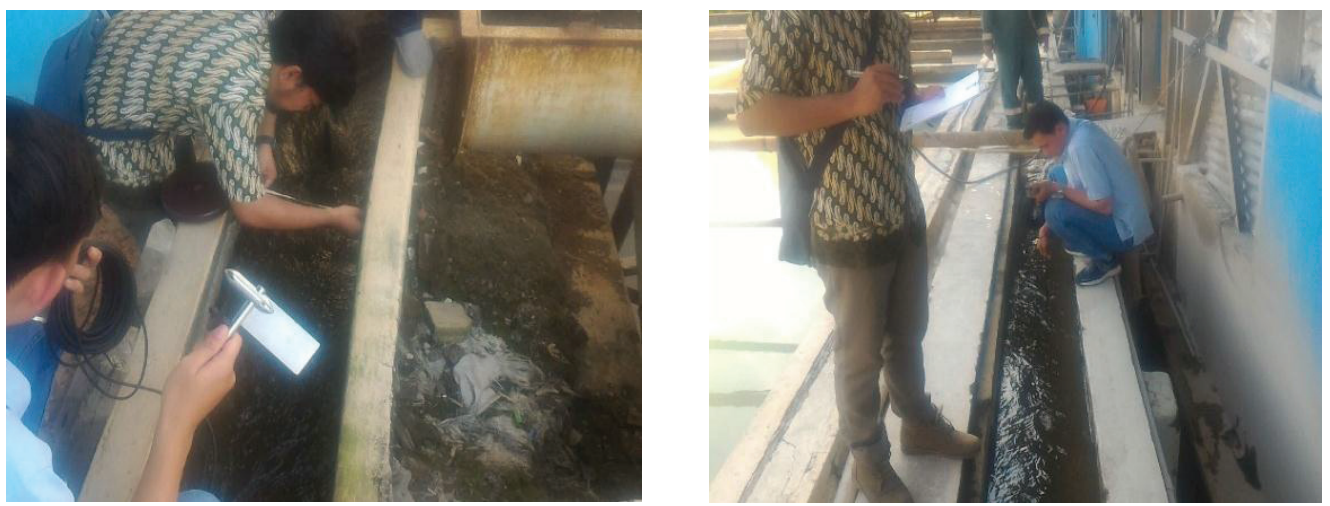

Gambar 12. Pengukuran pada titik pengamatan II

Pada titik pengamatan I ;

$$
\begin{aligned}
P \quad & =\frac{\rho \cdot A \cdot V^{3}}{2} \\
& \frac{1,000 \cdot(1 \times 0.35) \cdot 0.8^{3}}{2} \\
& =89.6 \mathrm{Watt}
\end{aligned}
$$

Pada titik pengamatan II ;

$$
P=\frac{1,000 \cdot(0.4 \times 0.4) \cdot 0.4^{3}}{2}
$$

Jadi daya listrik yang didapat bila dirancang pembangkit listrik hidrokinetik, sesuai dengan perhitungan, pada titik pengamatan I dapat terbangkit 89.6 Watt, sedang pada titik pengamatan II dapat terbangkit 5.12 Watt.

\section{Pembangkit listrik tenaga pikohidro (PLTPH) dengan Turbin Open Flume.}

Untuk menghitung daya yang terbangkitkan pada Pembangkit listrik tenaga pikohidro (PLTPH) dengan Turbin Open Flume, harus dimulai dengan menghitung daya hidraulik yang dikeluarkan dari jatuh air, dengan menggunakan persamaan (1) maka;

Pada titik pengamatan $\mathrm{I}$; (dengan asumsi $\mathrm{H}=$ 2 mtr)

$$
\begin{aligned}
\text { Pair } & =\rho \times \mathrm{g} \times \mathrm{Q} \times \mathrm{H} \\
& =1,000 \times 0.981 \times 0.28 \times 2 \\
& =549,36 \text { Watt }
\end{aligned}
$$

Dari hasil perhitungan daya hidraulik air (Pair) dapat dipakai untuk menghitung daya turbin $(\mathrm{Pt})$ yang dihasilkan, dengan menggunakan persamaan (2);

$$
\begin{aligned}
\text { Pt } & =\eta t \times \mathrm{T} \times \text { Pair } \\
& =0.90 \times 1 \times 549,36 \\
& =494.424 \text { Watt }
\end{aligned}
$$

Sehingga daya listrik (generator) yang dapat dibangkitkan dapat dihitung dengan persamaan (3),

$$
\begin{aligned}
\mathrm{Pg} & =\rho \times \mathrm{g} \times \mathrm{Q} \times \mathrm{H} \times \eta \mathrm{t} \\
& =1,000 \times 0.981 \times 0.28 \times 2 \times 0.9 \\
& =494.424 \text { Watt }
\end{aligned}
$$

Bila dengan asumsi $\mathrm{H}=1 \mathrm{mtr}$, pada titik pengamatan I, dapat dibangkitkan daya sebesar ;

$$
\begin{aligned}
\text { Pair } & =\rho \times g \times Q \times H \\
& =274.68 \text { Watt } \\
\text { Pt } & =\eta t \times T \times \text { Pair } \\
& =247.212 \text { Watt } \\
\text { Pg } & =\rho \times g \times Q \times H \times \eta t \\
& =247.212 \text { Watt }
\end{aligned}
$$

\section{Pada titik pengamatan II ;}

Titik pengamatan II sulit untuk direncanakan PLTPH dengan turbin open flume, karena sulitnya untuk merencanakan head atau tinggi jatuh air.

Dari hasil perhitungan diatas, pada titik pengamatan 1 dan 2 , berdasarkan table 1 , termasuk jenis pembangkit listrik tenaga piko hidro (PLTPH). 


\section{KESIMPULAN}

Pembangkit listrik tenaga hidrokinetik adalah pembangkit listrik yang memanfaatkan kecepatan aliran air, tanpa memperhitungkan head atau beda tinggi aliran air, dengan menggunakan turbin jenis Vertikal Axis tipe Darrieus -Straight Blade Cascade. Sedangkan pembangkit listrik tenaga pikohidro adalah pembangkit listrik berskala kecil dengan output di bawah $5 \mathrm{~kW}$ yang memanfaatkan potensi aliran air yang terdapat di pedesaan sebagai sumber tenaga misalnya saluran irigasi, sungai atau air terjun alam, dalam penulisan ini dengan memanfaatkan aliran kanal Kalisolo I.

Dilihat dari besar daya listrik yang terbangkitkan PLTPH mempunyai daya antara $<\mathrm{kW}$. Klasifikasi pembangkit listrik dibedakan berdasarkan besarnya daya yang terbangkitkan, klasifikasi tersebuat adalah : PikoHidro $<5$ kW, Mikro Hidro 5 - 100kW, Mini Hidro 100 1000kW, Small Hidro 1 - 15 MW, Medium Hidro 15 - 100 MW, dan Large Hidro > 100 MW.

Potensi energy listrik yang dapat dibangkitkan pada titik pengamatan I dan II, pada kanal Kalisolo I, berdasarkan data yang didapat dari pengukuran dan formulasi dari referensi adalah sebagai berikut :

Pada titik pengamatan I, bila direncanakan dengan pembangkit listrik hidro kinetic (PLTHk), dapat terbangkitkan daya listrik sebesar 89.6 Watt, sedang bila direncanakan dengan PLTPH dengan turbin open flume dapat terbangkitkan $0.5 \mathrm{~kW}$ dengan asumsi $\mathrm{H} ; 2$ meter, sedang bila dengan asumsi $\mathrm{H} ; 1$ meter, dapat terbangkitkan $0.25 \mathrm{~kW}$.

Pada titik pengamatan II, tidak bisa direncanakan penggunaan PLTPH turbin open flume, karena sulit untuk merencanakan tinggi jatuh air $(\mathrm{H})$, akan tetapi sesuai dengan data hasil pengukuran yang didapat, bila direncanakan PLMHk dapat terbangkitkan daya listrik sebesar 5.12 Watt.

Dengan melihat data yang didapat dan hasil dari perhitungan, maka yang lebih mungkin untuk direncanakan adalah dengan pembangkit listrik piko hidro (PLTPH) dengan turbin open flume.
Komponen atau peralatan yang diperlukan dalam perencanaan PLTPH turbin open flume adalah sebagai berikut ; turbin open flume, gearbox, generator, penstabil tegangan, transformator, kabel (penghantar).

\section{SARAN}

Dengan telah selesainya penelitian ini, penulis berharap agar dapat dilanjutkan ke perencanaan dan dapat direalisasikan ke bentuk phisik, untuk itu diperlukan dukungan dari manajemen.

\section{DAFTAR PUSTAKA}

Harsarapama, Prabu Anindiao. (2012). Turbin Mikrohidro Open Flume Dengan Hub Tip Ratio 0.4 Untuk Daerah Terpencil. Universitas Indonesia

Prajitno, teknologi Mekanikal dan Elektrikal Dalam PLTMH. Jakarta, 16 Desember 2013. Prayoga, Gama. 2008. Studi Potensi Pembangkit Listrik Tenaga Mikro Hidro Head Rendah Di Sungai Cisangkuy Kabupaten Bandung (Kajian Teknis). Bandung: Institut Teknologi Bandung.

Williamson, S.J and all. (2012). Low Head Pico Hydro Turbine Using a Multi Criteria Analysis. University of Bristol 